\title{
PRODUÇÃO ESCRITA PARA (DA) ACADEMIA EM CONTEXTO UNIVERSITÁRIO PÓS-BOLONHA: UMA REFLEXÃO CRÍTICA
}

\author{
WRITTEN PRODUCTION FOR (FROM) THE UNDERGRADUATE COURSE IN \\ POST-BOLOGNA UNIVERSITY CONTEXT: A CRITICAL OVERVIEW
}

\author{
Rosalice Pinto* \\ Universidade Nova de Lisboa, Lisboa, Portugal \\ Gorete Marques** \\ Instituto Politécnico de Leiria, Leira, Portugal \\ Marisa Dinis**** \\ Instituto Politécnico de Leiria, Leira, Portugal
}

\begin{abstract}
Resumo: Este artigo visa descrever a agentividade dos principais protagonistas (discentes e docentes) nas propostas apresentadas pela Declaração de Bolonha, em seu Decreto-Lei 74/2006, de 24 de março, e pelos programas implementados nas Faculdades de Direito das universidades públicas portuguesas. Seguindo pressupostos teóricos do Interacionismo Sociodiscursivo (BRONCKART et al, 2004), de uma Retórica da Ação como apontam Miller (1984) e Bazerman (2006) e contributos descritivos desenvolvidos por Fillmore $(1975,1977)$, poder-se-á observar que, nos documentos, os agentes principais são representados por papéis sintático-semânticos que não seriam expectáveis nestes textos. Tal constataçã̃o pode vir a atestar a existência de uma semiotização diferenciada entre a linguagem sobre o trabalho e a linguagem como trabalho, conceitos desenvolvidos por Nouroudine (2002). Procura-se mostrar, assim, através de determinado viéz descritivo, que o 'pretenso' objetivo da própria Declaração de Bolonha, o de estimular uma maior participação do aluno no processo de aprendizagem, de forma a tornáto mais autónomo e mais facilmente empregável no contexto europeu, pode vir a ser seriamente comprometido.
\end{abstract}

Palavras-chave: trabaho; agentividade; declaração de Bolonha; retórica da ação; interacionismo sociodiscursivo.

\footnotetext{
* Pesquisadora doutora do Centro de Linguística da Universidade Nova de Lisboa - CLUNL, e do Centro de Estudos sobre Direito e Sociedade da Universidade Nova de Lisboa - CEDIS, Lisboa, Portugal; rpinto@fcsh.unl.pt

* Professora doutora da Escola Superior de Tecnologia e Gestão do Instituto Politécnico de Leiria - IPLeiria; Investigadora do CELGA-ILTEC, Leiria, Portugal; gorete.marques@ipleiria.pt;

*** Professora doutora da Escola Superior de Tecnologia e Gestão do Instituto Politécnico de Leiria - IPLeiria; Investigadora do CIEJ, Leiria, Portugal; marisa.dinis@ipleiria.pt
} 
Linha D'Água (Online), São Paulo, v. 31, n. 1, p. 127-143, jan.-abril 2018

\begin{abstract}
This article aims at describing the agentivity of the main protagonists (students and teachers) in the proposals presented by the Bologna Declaration, in its Decree-Law 74/2006, of March 24, and by the programs implemented in the Faculties of Law of Portuguese public universities. Following the theoretical approach of Sociodiscursive Interactionism (BRONCKART et al, 2004), the Rhetoric of Action as pointed out by Miller (1984) and Bazerman (2006) and the descriptive contributions developed by Fillmore $(1975,1977)$, we can observe that, in the documents, the main agents are represented by syntactic-semantic roles that would not be expected in these texts. Such a finding may attest to the existence of a differentiated semiotization between language over work and language as work, concepts developed by Nouroudine (2002). The aim is to show, through a certain descriptive point, that the 'intended' goal of the Bologna Declaration itself, to stimulate a greater participation of the student in the learning process, in order to make it more autonomous and more easily employable in the European context, can be seriously compromised.
\end{abstract}

Keywords: Work; Agentivity; Bologna Declaration; Rhetoric of Action; Sociodiscursive Interactionism.

\title{
Introdução
}

A Declaração de Bolonha, assinada em junho de 1999 por $29^{1}$ Ministros da Educação de países europeus, veio alterar significativamente a política de ensino superior desses países. Nessa Declaração, previa-se que, até 2010, fosse estabelecido um Espaço Europeu de Ensino Superior compatível, competitivo e atrativo, que promovesse a mobilidade e empregabilidade e reduzisse as desigualdades sociais. ${ }^{2}$. Em Portugal, foi pelo Decreto-Lei 74/2006, de 24 de março, que foi legislada essa declaração e suas diretrizes foram implementadas nas diversas instituições de ensino superior que tiveram que adaptar os programas de ensino das suas unidades curriculares a este novo paradigma institucional.

Face a este contexto, este trabalho centrado em abordagens textuais-discursivas que relevam a importância da agentividade nas práticas sociais (BRONCKART, 1997) (BAZERMAN, 2006, MILLER, 1992), apresenta dois objetivos. Em primeiro lugar, visa a descrever de que forma a Declaração de Bolonha, através de suas diretrizes básicas, representa textualmente o papel dos agentes/actantes (docentes e discentes) para o desenvolvimento de competências, através da análise do papel sintático-semântico (FILLMORE, 1975 e BRONCKART e MACHADO, 2004) dos mesmos. Em segundo lugar, a partir de uma análise dos programas dos

1 Em 2009, 18 países aderiram ao processo de Bolonha.

2 A Declaração de Bolonha foi complementada em vários comunicados: Praga (2001), Berlim (2003), Bergen (2005), Londres (2007), Lovaina (2009), Budapeste e Viena (2010) e Bucareste (2012).

PINTO, R. B., MARQUES, M. G., DINIS, M. C. C. Produção escrita para (da) 
Linha D'Água (Online), São Paulo, v. 31, n. 1, p. 127-143, jan.-abril 2018

cursos das respectivas licenciaturas em Direito, verificar de que forma essa mesma agentividade é implementada. De acordo com os resultados obtidos, procederemos a uma reflexão crítica do impacto que Declaração de Bolonha trouxe para a academia, com a implementação de 'novos' programas das unidades curriculares em faculdades de Direito públicas portuguesas. O papel sintático-semântico dos diversos agentes (docentes e discentes) diretamente envolvidos nos documentos prescritivos (Decreto-Lei, programas das UC) nos parece um viés importante para o desenvolvimento dessa reflexão. Lembremos que um dos maiores objetivos da Declaração de Bolonha é tornar os alunos mais autónomos nas universidades de forma a torná-los mais preparados para o mercado de trabalho europeu.

Para atingir os objetivos propostos, aportaremos questões teóricas importantes dentro dos quadros teóricos já mencionados, o Interacionismo Sociodiscursivo e a Retórica da ação, além de trazermos alguns aportes importantes sobre o agir docente enquanto trabalho. Em seguida, procederemos às análises. Contudo, antes de desenvolvê-las, contextualizaremos cada um dos documentos que fazem parte do corpus de análise: por um lado, o Decreto-Lei introduzido através da Declaração de Bolonha e, por outro, os cinco programas das unidades curriculares das Faculdades de Direito públicas que tinham como objetivo desenvolver as competências dos alunos no âmbito da metodologia e análise do texto jurídico. Uma vez que estas disciplinas são ministradas, normalmente, por docentes com formações distintas (linguistas, filósofos, por exemplo), que relevam a importância da linguagem para a produção e circulação de saberes, o papel da agentividade nos programas de ensino por eles implementados poderia ser uma mais-valia para uma reflexão crítica.

\section{Quadro teórico}

Neste artigo, três pressupostos teórico-metodológicos de base do Interacionismo Sociodiscursivo - doravante ISD - (BRONCKART, 1997; 2004; 2008) merecem ser pontuados: (1) a importância da linguagem para o desenvolvimento do humano; (2) a pertinência de uma abordagem descendente na análise de textos inseridos em práticas sociais diversas; (3) a influência do entorno da produção 
Linha D'Água (Online), São Paulo, v. 31, n. 1, p. 127-143, jan.-abril 2018

(papel social dos participantes envolvidos, lugar, tempo, objetivo a ser atingido) na semiotização linguística.

Ademais, devem ser ressaltados alguns conceitos teóricos que serão importantes para a análise dos textos propostos. Por um lado, os conceitos de agir, agente, representação, desenvolvidos pelo ISD e, por outro, reflexões da Retórica da Ação sobre agentividade e produção escrita (BAZERMAN, 2006) que virão a 'dialogar' com questões pontuadas pelo quadro socio-interacionista discursivo.

$\mathrm{O}$ termo agir corresponde a qualquer forma de intervenção de um ou mais indivíduos no mundo e dentro dessa perspetiva teórica todos os seres humanos que intervêm no agir são denominados actantes. Contudo, estes, em suas ações, podem ser mais agentes ou atores. No segundo caso, apresentam capacidades, motivos e intenções bem demonstradas nas suas ações, o que não é perceptível no primeiro caso. Os actantes, ao produzirem textos de natureza psico-social-semiótica, mobilizam tanto representações individuais (singulares) quanto coletivas (estabilizadas socialmente) que coexistem e são re (atualizadas) quando das diversas interações sociais. É em função dessas representações que são efetuadas determinadas escolhas linguísticas que darão forma à construção das frases/textos. Estes actantes (termo genérico) utilizado por Bronckart é teorizado por Bazerman como "agente”. E é exatamente através da escrita que o aspecto agentivo do indivíduo é atestado, como aponta o último autor:

A escrita é imbuída de agência [...] A escrita está profundamente associada a valores de originalidade personalidade, individualidade - com razão, porque nos fornece os meios pelos quais deixamos traços de nossa existência, nossas condições de vida, nossos pensamentos, nossas ações e nossas intenções. Ainda mais, a escrita fornece-nos os meios pelos quais alcançamos outros através do tempo e do espaço, para compartilhar nossos pensamentos, para interagir, para influenciar e para cooperar. (BAZERMAN, 2006, p. 11)

De forma a termos uma padronização conceitual, manteremos o termo agente como genérico. Consideramos, assim, que as diversas vozes ${ }^{3}$ presentes

3 Segundo o ISD, os textos podem vir a ser descritos a partir de um folhado textual de três níveis (infra-estrutura textual; mecanismos de textualização e mecanismos enunciativos). Cada 
Linha D'Água (Online), São Paulo, v. 31, n. 1, p. 127-143, jan.-abril 2018

nos documentos, oriundas de indivíduos diversos, são agentes que, inseridos em práticas sociais, podem vir a ser apagadas ou evidenciadas em função do entorno das produções em que se estão integrados. Uma análise comparativa de natureza linguística dessa agentividade poderá vir a detectar divergências descritivas e consolidar algumas reflexões.

Merece ainda ser relevado que a produção escrita destes documentos oficiais é aqui considerada um trabalho ${ }^{4}$. É através das relações estabelecidas entre a linguagem e o trabalho que podemos verificar, seguindo pressupostos teórico-metodológicos distintos e complementares, três tipos de relação: linguagem sobre o trabalho, linguagem como trabalho e linguagem no trabalho (NOUROUDINE, 2002).

No nosso caso específico, advogamos, primeiramente, que o Decreto-Lei 74/2006, do ponto de vista textual discursivo, traz elementos linguísticos (linguagem sobre o trabalho) relevantes para que possamos evidenciar quais são as representações construídas pelos documentos oficiais sobre o que é esperado do trabalho educacional para a construção do agir docente/discente. $\mathrm{Na}$ verdade, corresponde ao agir prescritivo ou avaliativo a ser seguido pelos programas diversos nas diversas instituições. Além disso, assumimos que essa declaração é um gênero textual de natureza prescritiva, de cunho social ${ }^{5}$, o mesmo acontecendo com os programas de ensino das disciplinas que, ao reformularem informações contidas nas diretrizes oficiais, se focam em certos elementos em detrimento de outros e 'agenciam' diferentemente os diversos atores sociais que atuam no contexto

qual apresenta a sua especificidade. No caso dos mecanismos enunciativos, são apontados dois elementos de destaque: as modalizações e as vozes. Para detalhes, ver: (BRONCKART, 1997)

4 Consideramos nesta contribuição que o agir prescritivo (que dá origem aos documentos oficial e institucional) é um trabalho, sendo construído a partir de uma rede de discursos proferidos. Assumimos aqui uma definição ampla do termo trabalho à semelhança de Rocha et al (2002, p. 79-80).

5 Na verdade, a tradição bakhtiniana de definição do género como tipos estáveis de enunciados elaborados por cada língua foi retomada por diversos outros estudiosos dos textos e discursos, dentre eles Bronkart (1999). Contudo, neste trabalho, a produção de determinado género é uma ação retórica e, com isso, aproximamo-nos mais do conceito de gênero assumido por Miller (1984) e ratificado por Bazerman (2006). Para a autora estes são "ações retóricas tipificadas baseadas em situações recorrentes", socialmente instanciadas. - (MILLER, 1984, p. 159). 
Linha D'Água (Online), São Paulo, v. 31, n. 1, p. 127-143, jan.-abril 2018

acadêmico. Dentro desta contribuição, refletiremos exatamente de que forma os programas (que 'filtram institucionalmente' as diretrizes oficiais), ao optarem por determinados elementos linguístico-discursivos em detrimento de outros, podem vir a comprometer tanto os objetivos iniciais da própria Declaração de Bolonha, quanto a linguagem no trabalho dos professores.

A partir das questões teóricas apontadas, e ratificando a relevância da semiotização linguística (em especial da instauração da agentividade nesta contribuição) para uma reflexão sobre as representações dos docentes e discentes trazidas para a produção escrita dos vários documentos, resta-nos delimitar de que forma linguisticamente é instaurada essa representação agentiva. Para tal, optamos por delimitar os papéis sintático-semânticos exercidos pelos itens lexicais: "docente" e "estudante" e alguns dos seus sinônimos nos textos em análise. Na verdade, tal seleção não é aleatória, uma vez que uma das metas primordiais do documento oficial de Bolonha é desenvolver as competências agentivas do aluno e pressupõe-se, ao menos, que os programas produzidos pelos professores reproduzam tal intuito.

Em concreto, visamos perceber se é atribuída responsabilidade aos estudantes, isto é, se são agentivizados pelo texto ou se, pelo contrário, são instaurados com um papel que não lhes confere responsabilidade ou se não são representados linguisticamente. Para este efeito, baseamo-nos na classificação dos papéis dos protagonistas inspirada em Fillmore (1975), seguida por Bronckart e Machado (2004): (i) Agentivo (um ser animado é responsável por um processo); (ii) Instrumental (um ser inanimado é a causa imediata de um evento ou contribui para a realização de um processo dinâmico); (iii) Atributivo/Experenciador (é atribuída uma sensação ou um estado a uma entidade); (iv) Objetivo (a entidade sofre um processo dinâmico); (v) Beneficiário (o destinatário de um processo dinâmico é animado); (vi) Factivo (indica o estado ou o resultado final de uma ação). Inclusive, há de ser ressaltado que esta classificação não se pretende exaustiva, pelo que o mesmo autor estendeu a sua classificação (FILLMORE, 1977).

\section{Procedimentos de análise}


Linha D'Água (Online), São Paulo, v. 31, n. 1, p. 127-143, jan.-abril 2018

Para este estudo, centramos a análise em dois documentos: Decreto-Lei 74/2006 (Documento 1) de 24 de março e programas das unidades curriculares das instituições públicas (Documentos 2), identificadas na tabela (1) a seguir. O corpus é constituído por um total de 15.229 palavras (12.206 no Decreto-Lei e 3.023 nos programas).

No que diz respeito aos programas dos cursos de Direito ${ }^{6}$, interessa ressalvar que analisamos as unidades curriculares que, nos seus programas, atribuem relevância a questões relativas ao trabalho sobre a/ com a linguagem. Evidentemente, estas, em função dos objetivos institucionais, apresentam 'etiquetas' diversas nas Faculdades de Direito das diversas universidades: "Metodologia do Direito" (no caso da Universidade de Coimbra ou do Minho), ou ainda, "Metodologia e Filosofia Jurídica”, na Universidade do Porto; “Análise do Discurso Jurídico e Técnicas.

Tabela 1: Instituições públicas e unidades curriculares

\section{Instituição}

(1) Universidade de Coimbra

Faculdade de Direito

(2) Universidade de Lisboa

(3) Universidade Nova de Lisboa

(4) Universidade do Minho Escola de Direito

(5) Universidade do Porto Faculdade de Direito

\section{Unidade curricular}

Metodologia do Direito $\left(4 .^{\circ}\right.$ ano $/ 1 .^{\circ}$ semestre)

Não existe unidade curricular

Análise do Discurso Jurídico - $\mathrm{ADJ}-\left(2 .^{\circ}\right.$ ano $/ 2 .^{\circ}$ semestre $)$

Técnicas de Expressão (Legal Drafting) - TEL - $\left(4 .^{\circ}\right.$ ano/1. ${ }^{\circ}$ semestre)

Metodologia do Direito $\left(1 .^{\mathrm{o}}\right.$ ano $/ 2 .^{\circ}$ semestre $)$

Metodologia e Filosofia do Direito (4. ${ }^{\circ}$ ano $/ 1 .^{\circ}$ semestre)

Fonte: Tabela elaborada pelas autoras.

Os exemplos serão numerados em ordem crescente, contudo, quando oriundos dos programas das instituições acima, conterão o número cardinal (1), (2), (3), (4), (5), relativo à instituição ao qual se inserem.

6 Salientamos que, com o processo de Bolonha, as licenciaturas em Direito em Portugal passaram de cinco para quatro anos, tendo-se procedido, à semelhança das outras licenciaturas a alterações nos planos curriculares. 
Linha D'Água (Online), São Paulo, v. 31, n. 1, p. 127-143, jan.-abril 2018

\section{Percurso analítico}

Começaremos com a identificação dos papéis sintático-semânticos no Decreto -Lei 74/2006 e, posteriormente, nos programas das unidades curriculares das universidades públicas. Vale salientar que, tendo em conta o objetivo deste trabalho, não apresentamos uma classificação exaustiva dos agentes. Optaremos, contudo, por discutir algumas tendências de representação observadas e interpretá-las à luz dos aspetos teóricos anteriormente expostos.

Antes de procedermos à identificação desses papeis no Decreto-Lei 74/2006 e, posteriormente, nos programas das unidades curriculares das universidades públicas, faremos uma contextualização dos documentos analisados. Respeitaremos com isso uma abordagem descendente de análise como preconiza o ISD.

\section{Breve contextualização do documento (1)}

A Declaração de Bolonha, assinada em junho de 1999, como já mencionámos, apresentou propostas que procuravam modificar os paradigmas existentes até então no ensino superior. De forma sumária, listamos abaixo algumas dessas propostas:

1. Introdução de um sistema com graus académicos de fácil equivalência, incluindo a existência de um Suplemento ao Diploma;

2. Adopção de um sistema baseado em diferentes fases: o primeiro ciclo, a licenciatura, com uma duração mínima de três anos (de 180 a 240 créditos), o segundo ciclo, o mestrado (de 90 a 120 créditos), e o terceiro ciclo, o doutoramento; ${ }^{7}$

7 Em alguns casos, a formação exigida é superior, como explana o Decreto-Lei 74/2006: "Para algumas profissões - poucas - são internacionalmente exigidas formações mais longas, correspondentes a quatro, cinco ou seis anos curriculares de trabalho. Contam-se neste grupo, desde logo, aquelas que são objecto de normas comunitárias de coordenação das condições mínimas de formação, como as constantes da Directiva n. 2005/36/CE, do Parlamento Europeu e do Conselho, de 7 de Setembro (Jornal Oficial, n. L 255, de 30 de Setembro de 2005), 
Linha D'Água (Online), São Paulo, v. 31, n. 1, p. 127-143, jan.-abril 2018

3. Implementação de um sistema de créditos (ECTS - EuropeanCreditTransferSystem) os quais podem ser obtidos em contextos de ensino não-superior, desde que reconhecidos pelas instituições participantes. Com este sistema, os critérios para a atribuição de créditos a cada unidade curricular são harmonizados, considerando, para tal, o número de horas de trabalho para a realização da unidade curricular;

4. Incentivo à mobilidade de estudantes, professores, investigadores e pessoal administrativo;

5. Incentivo à cooperação na garantia da qualidade para desenvolver critérios e metodologias comparáveis;

6. Promoção da cooperação para o desenvolvimento de projetos e programas de estágio, de investigação inter-institucionais.

As medidas propostas visavam a convergência para o Espaço Europeu de Ensino Superior, mantendo o respeito pelas características de cada país.

Conforme supramencionado, com a padronização dos sistemas, reestruturam-se e harmonizam-se os graus académicos, bem como as suas designações, o que vem facilitar os processos de mobilidade e possibilitar o reconhecimento das qualificações. As alterações implicaram profundas reformas nomeadamente nos planos curriculares já existentes e no tipo de ensino-aprendizagem. Com efeito, se, no primeiro caso, o desafio centrava-se, em Portugal, na redução dos semestres letivos e, consequentemente, de unidades curriculares, no segundo caso o objetivo exigia uma mudança no paradigma de ensino-aprendizagem. Um dos objetivos de Bolonha foi estabelecer uma mudança no ensino-aprendizagem, centrando-o no estudante e não no docente, isto é, centrando o processo nas atividades realizadas pelo estudante, tornando-o mais ativo.

onde se incluem os médicos, os enfermeiros responsáveis por cuidados gerais, os médicos dentistas, os médicos veterinários, os enfermeiros especializados em saúde materna e obstetrícia, os farmacêuticos e os arquitectos. Por outro lado, aquelas cujas durações mais longas resultam de uma prática estável e consolidada na União Europeia, como é o caso de algumas áreas de engenharia de concepção. Finalmente, aquelas a que, por força de normas legais nacionais actualmente em vigor, deva ser fixada uma duração superior a 180 créditos." 
Linha D'Água (Online), São Paulo, v. 31 , n. 1, p. 127-143, jan.-abril 2018

A partir da Declaração de Bolonha, é legislado o Decreto-Lei 74/2006, de 24 de março, que visava concretizar claramente, em Portugal, "a passagem de um ensino baseado na transmissão de conhecimentos para um ensino baseado no desenvolvimento de competências" (DECRETO-LEI 74/2006, p. 2242)

O desafio para as instituições de ensino superior passou por saber identificar competências, desenvolver metodologias adequadas e aplicar este novo modelo, cumprindo o estipulado no referido Decreto-Lei. Em concreto, para o grau de licenciado, estipula, no art. ${ }^{\circ} .^{\circ}$ do Capítulo II:

O grau de licenciado é conferido aos que demonstrem:

a) Possuir conhecimentos e capacidade de compreensão numa área de formação a um nível que:

i) Sustentando-se nos conhecimentos de nível secundário, os desenvolva e aprofunde;

ii) Se apoie em materiais de ensino de nível avançado e lhes corresponda;

iii) Em alguns dos domínios dessa área, se situe ao nível dos conhecimentos de ponta da mesma;

b) Saber aplicar os conhecimentos e a capacidade de compreensão adquiridos, de forma a evidenciarem uma abordagem profissional ao trabalho desenvolvido na sua área vocacional;

c) Capacidade de resolução de problemas no âmbito da sua área de formação e de construção e fundamentação da sua própria argumentação;

d) Capacidade de recolher, selecionar e interpretar a informação relevante, particularmente na sua área de formação, que os habilite a fundamentarem as soluções que preconizam e os juízos que emitem, incluindo na análise os aspectos sociais, científicos e éticos relevantes;

e) Competências que lhes permitam comunicar informação, ideias, problemas e soluções, tanto a públicos constituídos por especialistas como por não especialistas; f) Competências de aprendizagem que lhes permitam uma aprendizagem ao longo da vida com elevado grau de autonomia.

\section{Análise do documento (1)}

Relativamente ao Decreto-Lei, identificámos 37 ocorrências para o termo estudante (considerando ainda os itens lexicais aluno, alunos, estudante e estudantes) e 
Linha D'Água (Online), São Paulo, v. 31, n. 1, p. 127-143, jan.-abril 2018

21 ocorrências para o docente (considerando os termos professores, docentes e o qualificativo docente). Quanto à representação sintático-semântica do(s) estudante(s), atestámos um maior número de ocorrências no papel de (i) Beneficiário. Contudo, observa-se também no papel de agente. Vejamos os exemplos a seguir:

(1) "A adequação das formações ao novo modelo de organização do ensino superior vem sendo concretizada através de um trabalho (...) que visa, designadamente (...) Assegurar aos estudantes portugueses condições de formação e de integração profissional similares (...)". [nosso sublinhado]

(2) "A determinação do trabalho que o estudante deve desenvolver em cada unidade curricular (...)"

No exemplo (1), os estudantes são representados como destinatários animados de um processo dinâmico, nomeadamente, pela adoção do Processo de Bolonha. Este pode assegurar de condições de mobilidade, de formação e de integração.

No exemplo (2), o valor agentivo do estudante é enfatizado: é o estudante responsável pelo desenvolvimento do seu trabalho. Contudo, este valor é mitigado, pelo próprio agir prescritivo ao qual está vinculado este trecho. O emprego do verbo dever, com valor deôntico (que se apresenta no documento com sujeitos distintos como estudantes, professores, estabelecimentos, normas, júri, adoção, formações, ciclos de estudos...). Porém, a representação agentiva com esta estrutura sintáctica concorre com o mesmo número de ocorrências com uma estrutura agentiva de complemento da passiva, conforme o exemplo seguinte:

(3) “(...) um trabalho em profundidade desenvolvido pelas instituições, que deve ser participado por estudantes e professores (...)"

Este último exemplo revela, a nosso ver, um aspeto fulcral: o de atribuir poder à entidade ("instituições”), colocando-as, no entanto, numa posição de relativo apagamento pela sua inserção numa construção passiva.

Os restantes papéis identificados - Instrumental, Atributivo e Objetivo - são identificados maioritariamente quando o termo aluno/estudante(s) surge como 
Linha D'Água (Online), São Paulo, v. 31, n. 1, p. 127-143, jan.-abril 2018

pós-modificador de entidades inanimadas, em sintagmas preposicionados que vêm contribuir para a realização de um processo dinâmico, como demonstram os exemplos a seguir:

(4) “As unidades curriculares a que se refere o número anterior (...) c) São creditadas em caso de inscrição do aluno no ciclo de estudos em causa.

(5) “A adopção do sistema europeu de créditos curriculares (ECTS-European Credit Transfer and Accumulation System), baseado no trabalho dos estudantes."

Relativamente à representação do docente, os resultados são idênticos aos identificados para o estudante, i.e., verifica-se um maior número de ocorrências do papel de Beneficiário e de Agente. Na verdade, parte das ocorrências é idêntica no sentido em que ambas as entidades - docente e estudante - são representados num mesmo enunciado, com a mesma atribuição de responsabilidade, como se pode observar no exemplo 3), anteriormente transcrito. Outros enunciados integram o docente como categoria (ex: professor-adjunto) ou como qualificativo antecedido dos nomes corpo ou Estatuto do Pessoal.

\section{Breve contextualização dos programas das unidades curriculares}

O programa de uma unidade curricular é o documento oficial que integra as informações sobre a mesma. Contém assim desde informações gerais (como a carga horária, o tipo de ensino, o número de ECTS ou pré-requisitos, entre outros) à bibliografia (obrigatória/complementar), passando pelos objetivos de aprendizagem/competências a desenvolver, pelo programa e método de avaliação. A sua estrutura varia de instituição para instituição, porém, fruto dos processos de avaliação e acreditação dos cursos de ensino superior, ${ }^{8}$ algumas instituições passaram a

8 Na sequência da aprovação do novo regime jurídico da qualidade do ensino superior (Lei n. 38/2007), foi criada a a Agência de Avaliação e Acreditação do Ensino Superior (A3ES), que tem como fins a avaliação e a acreditação das instituições de ensino superior e dos seus 
Linha D'Água (Online), São Paulo, v. 31, n. 1, p. 127-143, jan.-abril 2018

apresentar nos programas das unidades curriculares a estrutura exigida ${ }^{9}$ pelo guião de autoavaliação da A3ES. Tal não é o caso dos programas em análise neste estudo.

\section{Análise dos Documentos (2)}

Nos programas das unidades curriculares, verifica-se um número reduzido de ocorrências dos termos analisados. Para o caso de docente, identificámos a existência de um total de 6 ocorrências (sendo considerados, também, para esta contagem as unidades lexicais professor, professora, docente, regente e coordenador) e, para o estudante, um total de 11 ocorrências (sendo considerados, também, os termos estudante, estudantes, aluno e alunos). São os programas das unidades curriculares de Análise do Discurso (Universidade Nova de Lisboa) e o de Metodologia do Direito (Universidade do Minho) que apresentam o maior número de ocorrências.

O estudante e suas variantes são representados através de dois papéis: o de Beneficiário e o de Agente. Contudo, o maior número de ocorrências prende-se com o papel de Beneficiário (exemplo 8), por exemplo, seguindo-se o de Agente (exemplos 9 e 10), como observamos abaixo:

(8) (3) “- habilitar os estudantes a compreender a natureza autónoma do discurso enquanto suporte do sentido, bem como diversas abordagens teóricas orientadas para o analisar o discurso e captar o seu sentido;"

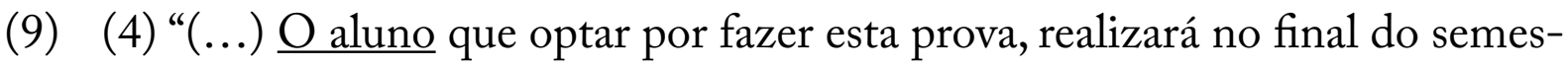
tre uma segunda prova a valer $75 \%$ do valor final."

\footnotetext{
ciclos de estudos, bem como o desempenho das funções inerentes à inserção de Portugal no sistema europeu de garantia da qualidade do ensino superior. As instituições tiveram, pois, de submeter as suas ofertas formativas a avaliação a fim de serem acreditadas.

9 No guião para a autoavaliação de ciclo de estudos em funcionamento (ACEF), a informação a incluir para cada unidade curricular é a seguinte: docente(s), carga letiva, objetivos de aprendizagem (conhecimentos, aptidões e competências a desenvolver pelos estudantes), conteúdos programáticos, demonstração da coerência dos conteúdos programáticos com os objetivos de aprendizagem da unidade curricular, metodologias de ensino (avaliação incluída), demonstração da coerência das metodologias de ensino com os objetivos de aprendizagem da unidade curricular e bibliografia de consulta/existência obrigatória.
} 
Linha D'Água (Online), São Paulo, v. 31, n. 1, p. 127-143, jan.-abril 2018

(10) (4) "Apreciação de trabalhos eventualmente apresentados pelos Senhores Estudantes (...)."

No exemplo (8) acima, o papel de Beneficiário exercido pelo estudante está relacionado, essencialmente, com um dos próprios objetivos do curso: o de capacitar o aluno a 'analisar discursos'. Tal questão é relevante, mas o aluno não é representado com um papel agentivo neste processo. Nos exemplos (9) e (10), o aluno é o agente. Contudo, nos dois últimos exemplos, esta agentividade relaciona-se mais a aspetos avaliativos do que ao próprio desenvolvimento de competências. Inclusive, vale ressaltar que, no exemplo (10), o uso da expressão modalizadora "eventualmente" enfraquece a própria agentividade atribuída pelo produtor textual ao estudante. Por outro lado, o uso da forma de tratamento "Senhor" que acompanha a unidade lexical "Estudantes" transmite um valor axiológico positivo ao termo, reforçando uma 'pretensa agentividade'.

No que tange ao termo docente, bem como aos itens lexicais a ele relacionados, observa-se que surge em sintagmas nominais padronizados, antecedendo a identificação dos regentes responsáveis pela lecionação das unidades curriculares. O papel sintático-semântico do termo pode ser considerado Atributivo (ou Experenciador). Observemos os exemplos a seguir:

(6) (3) "Professor responsável: xxxxxx"- (TEL)

(7) (4) "Professor responsável”- xxxxxxxxxx - (ADJ)

(8) (1) "Docente responsável xxxxx"

No entanto, encontramos num dos programas - exemplo (9) abaixo - um caso em que o docente é representado como Agente, no final do programa, dentro do item Bibliografia.

(9) (3) "Texto a fornecer pelo regente" 
Linha D'Água (Online), São Paulo, v. 31, n. 1, p. 127-143, jan.-abril 2018

\section{Considerações parciais}

A partir dos papéis sintático-semânticos atribuídos aos estudantes/alunos, observamos que estes são representados, prioritariamente, como 'beneficiários' tanto nos documentos oriundos da Declaração de Bolonha, quanto nos programas analisados das instituições públicas. Mesmo quando estes protagonistas são agentes, a agentividade relaciona-se a questões de avaliação e não ao desenvolvimento de competências. Tal constatação compromete um dos objetivos fulcrais da própria Declaração: tornar o estudante/aluno capaz de apresentar ideias e soluções, como atesta o art. ${ }^{\circ} .^{\circ}$ do Capítulo II. O desenvolvimento desta capacidade é inseparável de uma responsabilização do aluno no seu processo dinâmico de produção académica. No caso dos docentes, observa-se um elevado número de ocorrências em que estes são representados como beneficiários, no caso dos documentos oficiais e como experenciadores, nos programas. Tal aspecto ratifica a elevada padronização do gênero textual programa das UCs.

A análise da agentividade na linguagem sobre o trabalho/ como trabalho e sua semiotização linguística, nesta contribuição, deteve-se ao estudo dos papéis sintático-semânticos dos principais actantes: alunos e professores. Dessa forma, as conclusões a que chegamos são parciais. Resta-nos desenvolver outros trabalhos em que possamos analisar outras categorias linguísticas que possam vir a contribuir para caracterizar esta agentividade: as modalizações, os elementos de coesão textual, dentre outros. Dessa forma, seguindo uma perspectiva textual-discursiva, poderemos tecer considerações mais conclusivas.

\section{Corpus de análise}

Decreto-Lei 74/2006. Disponível em: <https://www.dges.gov.pt/pt/content/decreto-lei-no742006-de-24-de-marco-graus-e-diplomas-do-ensino-superior>. Acesso em: 24 Ago. 2017. 
Linha D'Água (Online), São Paulo, v. 31, n. 1, p. 127-143, jan.-abril 2018

Universidade Nova de Lisboa. Programa de Análise do Discurso Jurídico. Disponível em: <http://www.unl.pt/guia/2014/fd/UNLGI_getUC?uc=LL101>. Acesso em: 24 Ago. 2017.

Universidade do Minho. Programa de Metodologia do Direito. Disponível em: <https:// www.uminho.pt/pt/_layouts/15/uminho.portalum.ui/pages/catalogocursodetail.aspx?cid=1109001\&catid=5>. Acesso em: 24 Ago. 2017.

Universidade de Coimbra. Programa de Metodologia do Direito e seu Complemento. Disponível em: <https://apps.uc.pt/courses/PT/unit/22232/2361/2012-2013?common_core=true\&type=ram\&id=1556>. Acesso em: 24 Ago. 2017.

Universidade do Porto. Programa de Metodologia e Filosofia do Direito. Disponível em: <https://sigarra.up.pt/fdup/pt/ucurr_geral.ficha_uc_view?pv_ocorrencia_id=141143>. Acesso em: 24 Ago. 2017.

Universidade Nova de Lisboa. Programa de Técnicas de Expressão. Disponível em: <http:// www.unl.pt/guia/2014/fd/UNLGI_getUC?uc=LL140.A>. Acesso em: 24 Ago. 2017.

\section{Referências}

BAZERMAN, Charles. Gêneros, agência e escrita. São Paulo: Cortez, 2006.

BRONCKART, Jean-Paul. Atividades de linguagem, textos e discursos. Tradução Anna Rachel Machado e Péricles Cunha. São Paulo: Educ, 1997.

; MACHADO, Anna Rachel. Procedimentos de análise sobre o trabalho educacional. In; MACHADO, Anna Rachel. (org.). O Ensino sobre o trabalho. Uma abordagem discursiva. Londrina: Eduel, 2004, p. 131-166.

; al (ed.). Agir et discours en situation de travail. Cahiers de la Section en Sciences de l'Education (103), juin 2004.

FILLMORE, Charles J. An alternative to checklist theories of meaning. In : COGEN, C. Et al (ed.) Proceedings of the First Annual Meeting of the Berleley Linguistics Society. Berkeley: Berkeley Linguistics Society, 1975, p. 123-131. 
Linha D'Água (Online), São Paulo, v. 31, n. 1, p. 127-143, jan.-abril 2018

Scenes-and-frames semantics. In: Linguistics Structures Processing. Amsterdam and New York: North Holland Publishing Company, 1977, p. 55-81.

MILLER, Carolyn Genre as social action. Quarterly Journal of Speech (70), 1984, p. 151-67.

NOUROUDINE, Abdallah. A linguagem: dispositivo revelador da complexidade do trabalho. In. SOUZA e SILVA, M. C. e FAÏTA, D. (Orgs.). Linguagem e Trabalho: construção de objetos de análise no Brasil e na França. São Paulo: Cortez, 2002, p. 17-30.

ROCHA, Décio.; DAHER, Maria. Del Carmen F.; SANT'ANNA, Vera L. de A. Produtividade das investigações sobre o trabalho. In: SOUZA e SILVA, M. C. P. de e Faïta, D. (Orgs). Linguagem e trabalho: construção de objetos de análise no Brasil e na França. São Paulo: Cortez, 2002, p. 77-92.

Recebido em: 2/9/2017. Aprovado em: 30/10/2017. 